\section{Professor Hamid Ghodse}

Professor Hamid Ghodse, Director of the Centre for Addiction Studies and Chairman of the Department of Psychiatry of Addictive Behaviour at St George's Hospital Medical School in London, has been re-elected as President of the International Narcotics Control Board. The 13member Board, of which Professor Ghodse was President from 1993 to 1995 , is elected by the Economic and Social Council to monitor adherence to the international drug control treaties.

\section{The Mental Health Act Commission Panel}

The Mental Health Act Commission, which is responsible for the appointment of doctors to undertake the Second Opinions under the powers of Part IV of the Mental Health Act 1983, invites consultant psychiatrists of at least five year's standing to apply for appointment to its panel of available doctors. Doctors are particularly required for work in South West Wales, South Devon and Cornwall, East Anglia and Kent, although applications are welcome from all areas. Application forms are available from the Mental Health Act Commission, Maid Marion House, 56 Hounds Gate, Nottingham NG1 6BD (Tel: 01159437100$)$.

\section{Paintings in Hospitals open new gallery}

Paintings in Hospitals is a charitable trust that lends its unique collection of modern British Paintings to hospitals nationwide, thus supporting both the healthcare services and the arts. For the first time since its foundation in 1960, the collection will be on view to the general public at the Sheridan Russell Gallery, which will also act as Paintings in Hospital's new headquarters, from 29 April. For further information contact Marjorie Power, Director, on 01719350250.

\section{New publications}

Alzheimer's Disease Society leaflet

A specially designed leaflet is now available to teenagers having to cope with relatives who have Alzheimer's disease. Produced by the Alzheimer's Disease Society it points young people in the direction of the Society's helpline where they can get information, help and support. The helpline phone number is 01713060606 - open 9 am to $5 \mathrm{pm}$. For further information contact Veronica Fuller on 01713060813.

\section{Signpost}

The Signpost journal is a multi-disciplinary. quarterly journal aimed at qualified and unqualified staff working with older people with mental health needs and their carers. It has been produced by the Service Development Team (EMI) of Cardiff Community Healthcare NHS Trust over recent years for local Services and carers and has grown in stature to become more widely read and subscribed to. As a result of this a new look Signpost has been launched as a national journal. For more information telephone 0122249452.

Procedures in General Practice by Dr John Stuart Brown has recently been published by the BMJ Publishing Group. Priced at $\$ 24.95$ (UK) or $£ 27.00$ (Overseas), this compact, user friendly guide is designed to help Gps undertake minor surgery safely and with confidence. Each chapter is written by a leading specialist in the field, and the majority of authors are practising Gps.

\section{Autism: The International Journal}

The National Autistic Society (NAS) and Sage Publications have launched a new Journal to provide high quality articles on research-based practice into autism and related disorders. Potential contributors should contact Lesley Smeardon, NAS Publications Manager on 0181 450 4443. Subscription details: Jonathon Carter at Sage Publications on 0171374 0645/Fax: 0171374874

The Directory of Secure Forensic Psychiatric Facilities is a 90 page directory, first published in 1992 and recently updated and extended. It lists maximum, medium and low secure facilities throughout the UK and provides useful information to purchasers and providers of secure forensic accommodation. Further information: Forensic Directory, Visitors Centre, Rampton Hospital, Retford, Notts DN22 OPD (Tel: 01777 247571) 